\title{
Identical twins:one with anti-glomerular basement membrane glomerulonephritis,the other with systemic lupus erythematosus
}

\author{
Xiaoxia Liu', Yu Wu², Yuan Yang ${ }^{3}$, Jue Wang ${ }^{4}$, Ye Tao ${ }^{1}$, Ping Fu ${ }^{1}$ and Zhangxue Hü ${ }^{1 *}$
}

\begin{abstract}
Background: Anti-glomerular basement membrane (GBM) glomerulonephritis and systemic lupus erythematosus (SLE) are both disorders of the immune system; however, they are known as distinct diseases. Till now no clinical evidence suggests the genetic relationship between these two diseases. Herein, we present two identical twins; one was diagnosed as anti-GBM glomerulonephritis, the other SLE. This is the first clinical report on the genetic relationship between these two diseases.
\end{abstract}

Case presentation: A 25-year-old female was admitted complaining of intermittent gross hematuria for 6 months and elevated serum creatinine for 1 month. She denied hemoptysis. Laboratory examinations showed hemoglobin 7.4 $\mathrm{g} / \mathrm{dL}$, serum creatinine $7.15 \mathrm{mg} / \mathrm{dL}$ and albumin $2.8 \mathrm{~g} / \mathrm{dL}$. Urinalysis showed hematuria (484 RBCs per high-power field) and proteinuria 4+. Antinuclear antibody, complement levels and ANCAs were all normal. Renal ultrasound showed normal-sized kidneys without obstruction or masses. Serum anti-GBM antibody assay showed $119.70 \mathrm{RU} / \mathrm{mL}$ (normal range, $<20 \mathrm{RU} / \mathrm{mL}$ ). Chest $\mathrm{X}$-ray was normal. She was diagnosed as anti-GBM glomerulonephritis and received plasma exchange (2000-3000 $\mathrm{ml}$ plasma/exchange, 5 turns), methylprednisolone $0.5 \mathrm{~g}$ for three days, plus cyclophosphamide. Although serum anti-GBM antibodies decreased gradually to a normal range, her renal function did not improve. One month later, her identical twin sister was diagnosed as SLE based on malar erythema, arthralgia, antinuclear antibody positive with liter 1:1000, and Anti-Smith (Sm) antibody ++. Anti-GBM antibody and complements were within normal ranges. Further study showed these twins were HLA-DRB1*1501 homozygotes.

Conclusion: The presence of identical twins having anti-GBM nephritis and SLE respectively provides clinical evidence to support that anti-GBM nephritis and lupus may share a common genetic background to some extent, while environment may contribute to disease evolution in part.

Keywords: Anti-GBM nephritis, HLA-DRB1*1501, Systemic lupus erythematosus, Identical twins

\section{Background}

Lupus is a prototypic autoimmune disease and pathogenesis involves genetic predisposition and environmental conditions. Its highest reported concordance rate in monozygotic twins is up to 57\% [1]. Anti-GBM nephritis is also an autoimmune disease, but is much more rare and with a lower incidence compared to lupus. This disease can also occur in siblings and sets of identical twins [2]. However, there is no reported case of identical twins suffering from anti-GBM nephritis and lupus separately.

\footnotetext{
* Correspondence: hzxawy@scu.edu.cn

'Department of Nephrology, Chengdu, Sichuan Province, China

Full list of author information is available at the end of the article
}

We report a 25-year-old female developing anti-GBM nephritis, and her identical twin sister developing systemic lupus erythymatosus (SLE). Their HLA genotypes were both homozygous for HLA-DRB1*1501.

\section{Case presentation}

A 25-year-old female was admitted to our hospital complaining of intermittent gross hematuria for 6 months and elevated serum creatinine for 1 month. She was in good health until November of 2009, when she noticed gross hematuria without fever, dysuria, frequency, urgency, and suprapubic pain. Hematuria was noted every month, but she did not pay it any attention. In March of 2010, she noticed edema of her lower extremities and went to a

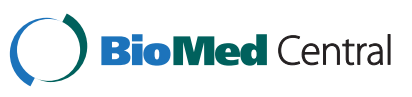


local hospital. Laboratory analysis showed urine protein $7.28 \mathrm{~g} / 24 \mathrm{~h}, \mathrm{RBC} 823$ per high-power field, Hemoglobin $8.5 \mathrm{~g} / \mathrm{dl}$, serum albumin $3.1 \mathrm{~g} / \mathrm{dL}$, creatinine $4.98 \mathrm{mg} / \mathrm{dL}$. One month later, she was transferred to our hospital. On physical examination, she presented with a pale face and edema of the lower extremities. Blood pressure was $150 / 100 \mathrm{mmHg}$, Hemoglobin was $7.4 \mathrm{~g} / \mathrm{dL}$, while the leukocyte and platelet counts were normal. Serum creatinine was $7.15 \mathrm{mg} / \mathrm{dL}$ and albumin $2.8 \mathrm{~g} / \mathrm{dL}$. Urinalysis showed hematuria (484 RBCs per high-power field) and proteinuria $4+$. Antinuclear antibody, complement levels and ANCAs were all negative or normal. Renal ultrasound showed normal-sized kidneys without obstruction or masses. Serum anti-GBM antibody assay by enzyme immunoassays (ELISA, EA 1251-9601 G, EUROIMMUN Medical Laboratory Diagnostics Co.,Ltd) showed 119.70 $\mathrm{RU} / \mathrm{mL}$ (normal range, $<20 \mathrm{RU} / \mathrm{mL}$ ). She became weaker and serum creatinine gradually elevated to $9.3 \mathrm{mg} / \mathrm{dL}$ while urine output decreased to $300 \mathrm{ml} /$ day. No hemoptysis developed and chest X-ray was normal.

The patient was diagnosed with anti-GBM nephritis, then treated with plasma exchange (2000-3000 ml plasma/exchange) plus hemodialysis every other day for 5 times, methylprednisolone $0.5 \mathrm{~g}$ for three days, plus cyclophosphamide $1 \mathrm{~g}$ for pulse infusion. Then her medications were shifted to oral prednisone $50 \mathrm{mg} /$ day. 2 weeks later, MP and CTX were administered again. Although serum anti-GBM antibody titer decreased gradually to normal, serum creatinine and urine outcome did not improve (Figure 1). Hemodialysis therapy continued.

Surprisingly, her identical twin sister came to our hospital complaining of malar erythema and arthralgia one month later. No hemoptysis, photosensitivity, edema and hematuria were recorded. Physical examination showed butterfly rash. No edema, oral ulcer, fever and hair loss. Hemoglobin was $13.1 \mathrm{~g} / \mathrm{dL}, \mathrm{WBC}$ was $5.46 \times 10^{9} / \mathrm{L}$, platelet was $116 \times 10^{9} / \mathrm{L}$, serum albumin was $4.17 \mathrm{~g} / \mathrm{dL}$ and creatinine was $0.56 \mathrm{mg} / \mathrm{dL}$. Urine protein was $0.1 \mathrm{~g} / 24 \mathrm{~h}$, No microscopic hematuria was revealed. Antinuclear antibody was positive with liter 1:1000, Smith (Sm) antibody ++, dsDNA antibody negative, ANCA negative. Anti-GBM antibody and complements were within their normal ranges (C3 $1.07 \mathrm{~g} / \mathrm{L}, \mathrm{C} 40.139 \mathrm{~g} / \mathrm{L})$. Based on the diagnostic criteria of SLE in 1982 of American College of Rheumatology, she was diagnosed as SLE. Oral prednisone $40 \mathrm{mg} /$ day was initiated and tapered regularly with alleviation of her rash and arthralgia. Two years later, malar erythema relapsed with lowered C3 0.652 g/L. Prednisone was increased to $40 \mathrm{mg} /$ day combined with leflunomide $20 \mathrm{mg} /$ day and hydroxychloroquine $400 \mathrm{mg} /$ day. Her rash faded again. At the end of follow up, serum creatinine was $0.71 \mathrm{mg} / \mathrm{dL}$, serum albumin was $4.18 \mathrm{~g} / \mathrm{dL}$, hemoglobin was $14.2 \mathrm{~g} / \mathrm{dL}, \mathrm{WBC}$ was $4.25 \times 10^{9} / \mathrm{L}$, platelet was $114 \times 10^{9} / \mathrm{L}$, anti-GBM antibody was still within normal range.

Considering HLA-DRB1*1501 alleles are associated with susceptibility to anti-GBM nephritis and lupus, we analyzed HLA-DRB1 alleles in these two sisters, and they were both HLA-DRB1*1501 homozygotes.

\section{Conclusions}

Anti-GBM nephritis is a rare autoimmune disorder characterized by elevated serum anti-GBM antibodies and rapidly progressive glomerulonephritis. Renal biopsy reveals crescent glomerulonephritis with linear IgG deposit

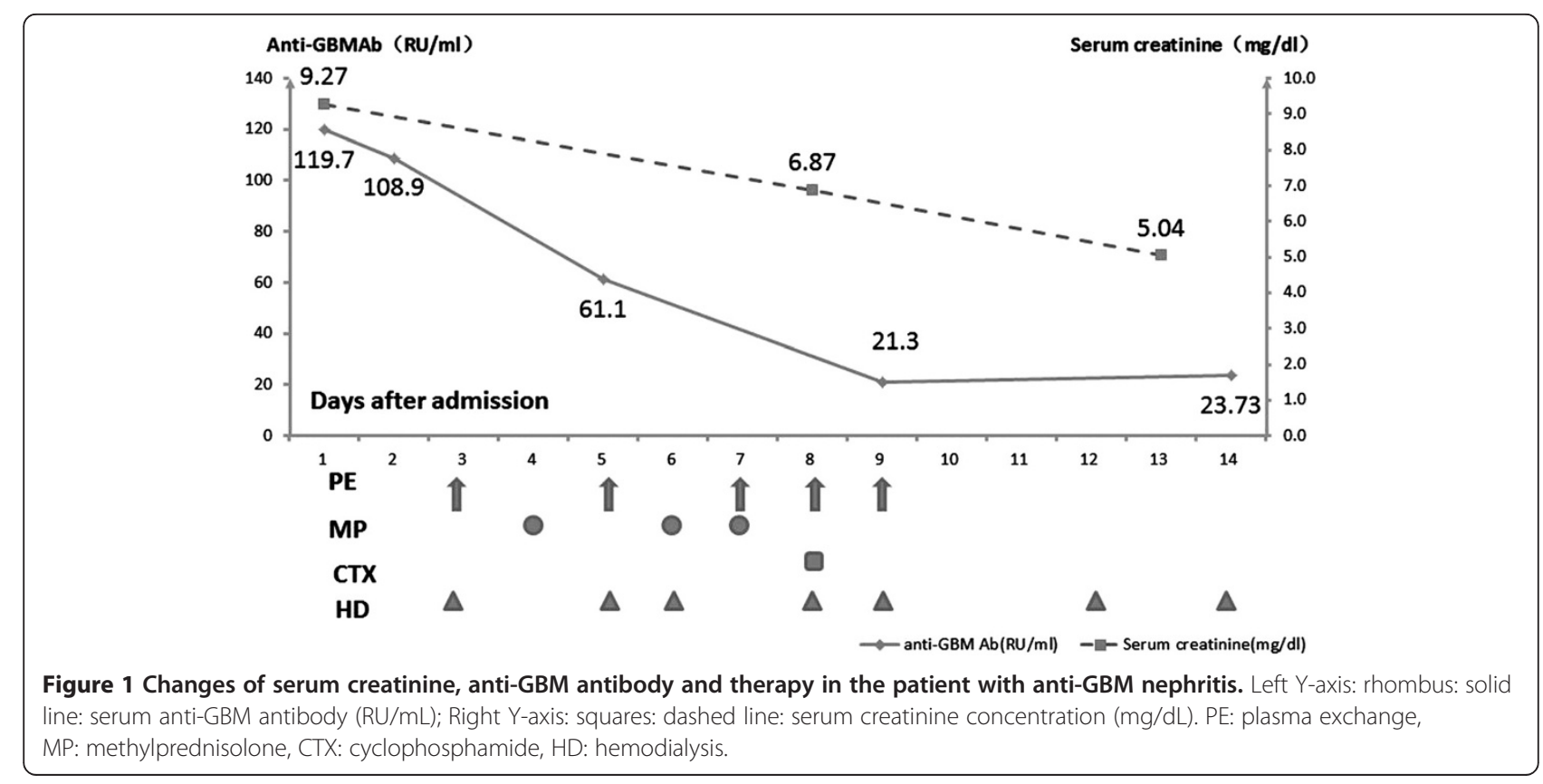


along capillary walls. When pulmonary hemorrhage is also present, this condition is called Goodpasture's Syndrome [3]. The first patient presented gross hematuria and rapid deterioration of renal function with significantly elevated anti-GBM antibodies and negative ANCA and ANA. Although renal biopsy was not conducted, anti-GBM nephritis was diagnosed based on elevated anti-GBM antibody and clinical manifestations of rapidly progressive glomerulonephritis. Although plasma exchange and pulse treatment of MP and CTX had been applied, she was still dialysis-dependent. The outcomes of anti-GBM nephritis depend on renal function at presentation and percentage of crescents on renal biopsy [4]. Considering she was dialysis-dependent and serum creatinine exceeded $9 \mathrm{mg} / \mathrm{dL}$ at presentation, chance of renal survival should be less than $8 \%$ [4]. Interestingly,her identical twin sister developed lupus with negative anti-GBM antibody later. Till now, it has not been reported that identical twins developed either lupus or anti-GBM nephritis.

There are evidently differences in pathogenesis, clinical manifestations and outcomes between anti-GBM glomerulonephritis and lupus. For example, anti-GBM nephritis is associated with anti-GBM antibody and rarely relapses, while lupus involves many antibodies including ANA, dsDNA, Smith(Sm) antibody, and is a life-long disorder that may relapse. It has long been believed that anti-GBM nephritis is different from other autoimmune disorders.

Recently, there is evidence suggesting that there is relationship between lupus and anti-GBM nephritis. C-H $\mathrm{Li}$ et al. found that anti-GBM antibody was detected in 14 (8.9\%) of 157 patients with SLE [5]. All of the 14 patients developed lupus nephritis; ten of them reached the criteria for crescentic glomerulonephritis and five of them were diagnosed as Goodpasture's disease. A few cases also showed coexistence of anti-GBM glomerulonephritis and lupus [6,7]. It was suggested that ongoing glomerular inflammation may change GBM structure, triggering an autoimmune reaction by exposing or modifying antigens, as proposed for the association between anti-GBM disease and ANCA glomerulonephritis [8]. However, identification of twins diagnosed as anti-GBM glomerunephritis and lupus respectively could not be attributed to this hypothesis. It seems that some genetic connection may exist between these two diseases.

Human leukocyte antigen (HLA), which plays an important role in immune responses, consists of the class I and class II molecules. Class II molecules are required for the presentation of antigens to $\mathrm{T}$ cell receptors and contribute to the production of specific antibodies. Genetic defects in self-tolerance can be triggered by reduced or altered expression of HLA molecules, which may aggravate the progression of different antoimmune diseases [9]. Genes in the HLA complex are among the strongest predisposing genetic factors. HLA-DRB1*1501 has been associated with susceptibility to anti-GBM disease. The frequency of HLA-DRB1*1501 in anti-GBM antibody-positive Japanese and Chinese patients was significantly higher than controls (36/88 vs $64 / 400$, $\mathrm{P}=1.597 \times 10^{-7}$, in China) $[10,11]$. HLA-DRB1*1501 alleles were also significant risk factors for SLE $[9,12]$. DRB1*1501/DQB1*0602 was identified as one of three microsatellite-inferred risk haplotypes in European lupus families [13]. HLA-DRB1*1501 allele are strongly associated with multiple sclerosis in African-American [14]. The mechanism underlying HLA association with autoimmune diseases is not clearly understood until now. Although it is difficult to define HLA-DRB1*1501 as a molecular biomarker of anti-GBM nephritis or lupus, the fact that these identical twins were both HLA-DRB1*1501 homozygotes supports the possible association of this allele with anti-GBM and lupus.

The latest research shows that out of about 25 different molecules in anti-GBM nephritis mouse model and spontaneous lupus nephritis (SLN), all influenced both diseases concordantly, including complement-and FcR-dependent activation of resident renal cells and infiltrating leukocytes, proinflammatory mediators initially, and profibrotic molecules [15]. Since SLN in mouse models takes 6-12 months to manifest, the experimental anti-GBM nephritis model has been used as a useful tool to unravel the molecular basis of SLN.

It is exciting that kallikrein genes may be the common candidate genes for lupus and anti-GBM nephritis in animal models [16]. Briefly, some murine strains, including $N Z W, D B A / 1$, are highly sensitive to experimental anti-GBM nephritis, while other strains such as C57BL/6 (B6) are resistant [17]. A microarray-based transcriptomic analysis revealed that the kallikrein $(K L K)$ gene family may be the key to produce these differences between these strains [16]. The tissue kallikrein gene cluster is located within the Sle3 interval [18], one of potential pathogenic loci in SLE. B6. Sle ${ }^{z}$ mice (bearing the NZM2410/NZMderived "z" allele of Sle3 on the relatively normal B6 background), exhibited increased susceptibility to experimental anti-GBM-induced nephritis compared with wide-type B6 [16]. Delivery of $k l k 1$ encoding KLK1(the principal kinin-generating enzyme) to B6. Sle3 congenics ameliorated anti-GBM-induced nephritis [19]. Interestingly, B6. NZMc1|c7 mice (bicongenic for Sle1 and Sle3) could produce significantly elevated glomerular-binding autoantibodies compared with B6 [20]. These findings indicated that kallikreins play an important role in these diseases, and could constitute a potential candidate genes for anti-GBM nephritis and SLN.

Although evidence mentioned above demonstrates similarities of genetic backgrounds between lupus and anti-GBM nephritis, after all, the huge differences of their clinical features still exist. Why would these twins 
bearing identical genetic backgrounds develop such different diseases respectively? Although genetic predisposition plays an important role in these diseases, it is generally accepted that environmental factors modulate the susceptibility, in part, through epigenetic changes. The concordance rate of lupus in identical twins is greater than in the general population, but it is still incomplete $[1,21,22]$. Many epidemiologic and environmental elements such as ethnicity, gender, hormonal exposure, UV radiation, pregnancy, smoking habits, and viral exposures are thought to influence these phenotypic variations. Recent studies showed that epigenetic alterations play an important role on the pathogenesis of SLE, including the global loss of DNA methylation and altered patterns of histone modifications [23]. Although anti-GBM glomerulonephritis may occur in siblings and sets of identical twins [2], there are few epigenetic study of this disease because of the rarity. Environmental factors including exposure to hydrocarbons and smoking have been thought to associate with the onset and progression of anti-GBM glomerulonephritis, which is different from SLE. Because pathogenic mechanisms involving the onset and progression of these diseases are far from clear, although the twins seemed to grow up in the same environment and shared the same genetic background, it is possible that some unknown environmental factors triggered the onsets of diverse diseases. Although the girl suffering from SLE has normal serum anti-GBM antibody, she may also develop anti-GBM glomerulonephritis in the future under some situation, and vice versa.

We present two identical twins that developed anti-GBM nephritis and lupus respectively, which supports a connection between these diseases, which need to be investigated further. Environmental factors may contribute to final clinical differences.

\section{Consent}

Written informed consent was obtained from both patients for publication of this Case report and any accompanying images. A copy of the written content is available for review by the Editor of this journal.

\section{Abbreviations \\ SLE: Systemic lupus erythematosus; GBM: Glomerular basement membrane; HLA: Human leukocyte antigen; ANCA: Anti-neutrophil cytoplasmic antibody; MP: Methylprednisolone; CTX: Cyclophosphamide.}

\section{Competing interests}

None of the authors has any competing interests.

\section{Authors' contributions}

$X X L, Y W, Y T, P F$ and $Z X H$ were the physicians who treated the patient in this report. $Y Y$ and JW performed genetic studies. The manuscript was prepared by $X X L, Y W, Y Y, J W, Y T, P F$ and $Z X H$. All authors participated in discussions about the manuscript and approved the final version.

\section{Acknowledgements}

The work was supported by grants from national key technologies R\&D program (grant number: 2006BAI05A08, PR. China) and a grant from Sichuan province key technologies R\&D program (grant number: 2009 SZ0143 and 2013FZ0061).

\section{Author details}

${ }^{1}$ Department of Nephrology, Chengdu, Sichuan Province, China

${ }^{2}$ Department of Hematology and Hematology Research Laboratory, Chengdu, Sichuan Province, China. ${ }^{3}$ Department of Medical Genetics-all in National Key Laboratory of Biotherapy of Human Diseases, West China Hospital, Sichuan University, Chengdu, Sichuan Province, China. ${ }^{4}$ Institute of Blood Transfusion, Chinese Academy of Medical Science, Chengdu, Sichuan Province, China.

Received: 23 February 2013 Accepted: 25 November 2013

Published: 20 December 2013

\section{References}

1. Block SR, Winfield JB, Lockshin MD, D'Angelo WA, Christian CL: Studies of twins with systemic lupus erythematosus. A review of the literature and presentation of 12 additional sets. Am J Med 1975, 59(4):533-552.

2. Pusey CD: Anti-glomerular basement membrane disease. Kidney Int 2003, 64(4):1535-1550.

3. Salama AD, Levy JB, Lightstone L, Pusey CD: Goodpasture's disease. Lancet 2001, 358(9285):917-920.

4. Levy JB, Turner AN, Rees AJ, Pusey CD: Long-term outcome of anti-glomerular basement membrane antibody disease treated with plasma exchange and immunosuppression. Ann Intern Med 2001, 134(11):1033-1042.

5. Li CH, Li YC, Xu PS, Hu X, Wang CY, Zou GL: Clinical significance of anti-glomerular basement membrane antibodies in a cohort of Chinese patients with lupus nephritis. Scand J Rheumatol 2006, 35(3):201-208.

6. Ho J, Gibson IW, Zacharias J, Fervenza F, Colon S, Borza DB: Antigenic heterogeneity of IgA anti-GBM disease: new renal targets of IgA autoantibodies. Am J Kidney Dis 2008, 52(4):761-765.

7. Richards NT, Lueck C, Davies DR, Jones NF, Al-Khadar A, Coode P: Anti-glomerular basement membrane antibody and linear glomerular immunofluorescence in a patient with systemic lupus erythematosus. Clin Nephrol 1988, 30(2):115-116.

8. Hellmark T, Niles JL, Collins AB, McCluskey RT, Brunmark C: Comparison of anti-GBM antibodies in sera with or without ANCA. J Am Soc Nephrol 1997, 8(3):376-385

9. Fernando MMA, Stevens CR, Walsh EC, De Jager PL, Goyette P, Plenge RM, Vyse TJ, Rioux JD: Defining the Role of the MHC in Autoimmunity: A Review and Pooled Analysis. PLoS Genet 2008, 4(4):e1000024.

10. Kitagawa W, Imai H, Komatsuda A, Maki N, Wakui H, Hiki Y, Sugiyama S: The HLA-DRB1*1501 allele is prevalent among Japanese patients with anti-glomerular basement membrane antibody-mediated disease. Nephrol Dial Transplant 2008, 23(10):3126-3129.

11. Yang R, Cui Z, Zhao J, Zhao MH: The role of HLA-DRB1 alleles on susceptibility of Chinese patients with anti-GBM disease. Clin Immunol 2009, 133(2):245-250.

12. Pan CF, Wu CJ, Chen HH, Dang CW, Chang FM, Liu HF, Chu CC, Lin M, Lee YJ: Molecular analysis of HLA-DRB1 allelic associations with systemic lupus erythematous and lupus nephritis in Taiwan. Lupus 2009, 18(8):698-704.

13. Graham RR, Ortmann WA, Langefeld CD, Jawaheer D, Selby SA, Rodine PR, Baechler EC, Rohlf KE, Shark KB, Espe K, et al: Visualizing human leukocyte antigen class II risk haplotypes in human systemic lupus erythematosus. Am J Hum Genet 2002, 71(3):543-553.

14. Oksenberg JR, Barcellos LF, Cree BA, Baranzini SE, Bugawan TL, Khan O, Lincoln RR, Swerdlin A, Mignot E, Lin L, et al: Mapping multiple sclerosis susceptibility to the HLA-DR locus in African Americans. Am J Hum Genet 2004, 74(1):160-167.

15. Du Y, Fu Y, Mohan C: Experimental anti-GBM nephritis as an analytical tool for studying spontaneous lupus nephritis. Arch Immunol Ther Exp (Warsz) 2008, 56(1):31-40.

16. Liu K, Li QZ, Delgado-Vega AM, Abelson AK, Sanchez E, Kelly JA, Li L, Liu Y, Zhou J, Yan M, et al: Kallikrein genes are associated with lupus and glomerular basement membrane-specific antibody-induced nephritis in mice and humans. J Clin Invest 2009, 119(4):911-923. 
17. Xie C, Sharma R, Wang H, Zhou XJ, Mohan C: Strain distribution pattern of susceptibility to immune-mediated nephritis. I Immunol 2004, 172(8):5047-5055.

18. Liu K, Li QZ, Yu Y, Liang C, Subramanian S, Zeng Z, Wang HW, Xie C, Zhou XJ, Mohan C, et al: Sle3 and Sle5 can independently couple with Sle1 to mediate severe lupus nephritis. Genes Immun 2007, 8(8):634-645.

19. Li QZ, Zhou J, Yang R, Yan M, Ye Q, Liu K, Liu S, Shao X, Li L, Zhou XJ, et al: The lupus-susceptibility gene kallikrein downmodulates antibody-mediated glomerulonephritis. Genes Immun 2009, 10(5):503-508.

20. Mohan C, Morel L, Yang P, Watanabe H, Croker B, Gilkeson G, Wakeland EK Genetic dissection of lupus pathogenesis: a recipe for nephrophilic autoantibodies. J Clin Invest 1999, 103(12):1685-1695.

21. Grennan DM, Parfitt A, Manolios N, Huang Q, Hyland V, Dunckley H, Doran T, Gatenby P, Badcock C: Family and twin studies in systemic lupus erythematosus. Dis Markers 1997, 13(2):93-98.

22. Deapen D, Escalante A, Weinrib L, Horwitz D, Bachman B, Roy-Burman P, Walker A, Mack TM: A revised estimate of twin concordance in systemic lupus erythematosus. Arthritis Rheum 1992, 35(3):311-318.

23. Javierre BM, Richardson B: A new epigenetic challenge: systemic lupus erythematosus. Adv Exp Med Biol 2011, 711:117-136.

doi:10.1186/1471-2369-14-277

Cite this article as: Liu et al.: Identical twins:one with anti-glomerular basement membrane glomerulonephritis,the other with

systemic lupus erythematosus. BMC Nephrology 2013 14:277.

\section{Submit your next manuscript to BioMed Central and take full advantage of:}

- Convenient online submission

- Thorough peer review

- No space constraints or color figure charges

- Immediate publication on acceptance

- Inclusion in PubMed, CAS, Scopus and Google Scholar

- Research which is freely available for redistribution 